\title{
Broad-Spectrum Antiviral Activity of 3D8, a Nucleic Acid-Hydrolyzing Single-Chain Variable Fragment (scFv), Targeting SARS-CoV-2 and Multiple Coronaviruses In Vitro
}

\author{
Gunsup Lee ${ }^{1, \dagger}{ }^{+}$Shailesh Budhathoki ${ }^{2,+} \oplus$, Geum-Young Lee ${ }^{3}$, Kwang-ji Oh ${ }^{1}$, Yeon Kyoung Ham ${ }^{1}$, \\ Young-Jun Kim ${ }^{1}$, Ye Rin Lim ${ }^{1,4}$, Phuong Thi Hoang ${ }^{5}$, Yongjun Lee ${ }^{5}$, Seok-Won Lim ${ }^{6}$, Jun-Mo Kim ${ }^{6}{ }^{\circ}$, \\ Seungchan $\mathrm{Cho}^{3}$, Tai-Hyun Kim ${ }^{1}$, Jin-Won Song ${ }^{3,7}$, Sukchan Lee ${ }^{5, *,+}$ and Won-Keun Kim ${ }^{2,4, *,+} \mathbb{D}$
}

Citation: Lee, G.; Budhathoki, S.; Lee, G.-Y.; Oh, K.-j.; Ham, Y.K.; Kim, Y.-J.; Lim, Y.R.; Hoang, P.T.; Lee, Y.; Lim, S.-W.; et al. Broad-Spectrum Antiviral Activity of 3D8, a Nucleic Acid-Hydrolyzing Single-Chain Variable Fragment (scFv), Targeting SARS-CoV-2 and Multiple Coronaviruses In Vitro. Viruses 2021, 13, 650. https://doi.org/10.3390/ v13040650

Academic Editor: Cheng-Wen Lin

Received: 11 March 2021

Accepted: 7 April 2021

Published: 9 April 2021

Publisher's Note: MDPI stays neutral with regard to jurisdictional claims in published maps and institutional affiliations.

Copyright: (c) 2021 by the authors. Licensee MDPI, Basel, Switzerland. This article is an open access article distributed under the terms and conditions of the Creative Commons Attribution (CC BY) license (https:/ / creativecommons.org/licenses/by/ $4.0 /)$.
1 R\&D Center, Novelgen Co., Ltd., 77, Changnyong-daero 256 beon-gil, Yeongtong-gu, Suwon-si 16229, Korea; leegs@novelgen.co.kr (G.L.); kjoh@novelgen.co.kr (K.j.O.); ykham@novelgen.co.kr (Y.K.H.); yjkim@novelgen.co.kr (Y.-J.K.); limyr0412@naver.com (Y.R.L.); thkim@novelgen.co.kr (T.-H.K.)

2 Department of Microbiology, College of Medicine, Hallym University, Chuncheon 24252, Korea; shailesh.sas24@gmail.com

3 Department of Microbiology, Korea University College of Medicine, Seoul 02841, Korea; gemyeng002@korea.ac.kr (G.-Y.L.); schanchan@korea.ac.kr (S.C.); jwsong@korea.ac.kr (J.-W.S.)

4 Institute of Medical Science, College of Medicine, Hallym University, Chuncheon 24252, Korea

5 College of Biotechnology and Bioengineering, Sungkyunkwan University, Suwon 16419, Korea; hoangphuong06cs@gmail.com (P.T.H.); 88yj111@naver.com (Y.L.)

6 Animal Functional Genomics \& Bioinformatics Lab., Department of Animal Science and Technology, Chung-Ang University, Anseong 17546, Korea; sw8333@cau.ac.kr (S.-W.L.); junmokim@cau.ac.kr (J.-M.K.)

7 BK21 Graduate Program, Department of Biomedical Sciences, Korea University College of Medicine, Seoul 02841, Korea

* Correspondence: cell4u@skku.edu (S.L.); wkkim1061@hallym.ac.kr (W.-K.K.)

+ These authors contributed equally to this work.

Abstract: The virus behind the current pandemic, severe acute respiratory syndrome coronavirus 2 (SARS-CoV-2) is responsible for the etiology of novel coronavirus disease (COVID-19) and poses a critical public health threat worldwide. Effective therapeutics and vaccines against multiple coronaviruses remain unavailable. Single-chain variable fragment (scFv), a recombinant antibody, exhibits broad-spectrum antiviral activity against DNA and RNA viruses owing to its nucleic acidhydrolyzing property. The antiviral activity of 3D8 scFv against SARS-CoV-2 and other coronaviruses was evaluated in Vero E6 cell cultures. Viral growth was quantified with quantitative RT-qPCR and plaque assay. The nucleic acid-hydrolyzing activity of 3D8 was assessed through abzyme assays of in vitro viral transcripts and cell viability was determined by MTT assay. We found that 3D8 inhibited the replication of SARS-CoV-2, human coronavirus OC43 (HCoV-OC43), and porcine epidemic diarrhea virus (PEDV). Our results revealed the prophylactic and therapeutic effects of 3D8 scFv against SARS-CoV-2 in Vero E6 cells. Immunoblot and plaque assays showed the reduction of coronavirus nucleoproteins and infectious particles, respectively, in 3D8 scFv-treated cells. These data demonstrate the broad-spectrum antiviral activity of 3D8 against SARS-CoV-2 and other coronaviruses. Thus, it could be considered a potential antiviral countermeasure against SARS-CoV-2 and zoonotic coronaviruses.

Keywords: SARS-CoV-2; COVID-19; coronaviruses; single-chain variable fragment; 3D8 scFv

\section{Introduction}

Coronaviruses (subfamily Orthocoronavirinae in the family Coronaviridae of the order Nidovirales) are a group of enveloped viruses containing a single-stranded positive-sense RNA genome [1,2]. Divergent coronaviruses constitute four genetic lineage groups, namely alphacoronaviruses, betacoronaviruses, gammacoronaviruses, and deltacoronaviruses. These viruses infect a broad range of natural reservoir hosts, including humans, bats, 
rodents, pigs, and camels [3]. Currently, six coronavirus species are known to cause infectious diseases in humans. Four coronaviruses, human coronavirus OC43 (HCoV-OC43), 229E, NL63, and HKU1, induce flu-like common cold symptoms in immunocompromised individuals [4]. Two highly transmissible and pathogenic viruses, severe acute respiratory syndrome coronavirus 1 (SARS-CoV-1) and Middle East respiratory syndrome coronavirus (MERS-CoV), are associated with fatal illness involving pneumonia and respiratory disorders [5]. In late December 2019, the city of Wuhan in the Hubei province of China reported several cases of patients with severe pneumonia [6], which was identified as the novel coronavirus disease (COVID-19) caused by SARS-CoV-2 [7]. SARS-CoV-2 utilizes a host cell receptor, angiotensin-converting enzyme 2 (ACE-2), for entry. The viral evasion is facilitated by transmembrane serine protease 2 (TMPRSS2) through spike protein fusogenic activity $[8,9]$. This novel strain is genetically distinct from SARS-CoV-1, despite both being members of lineage 2 betacoronaviruses [10]. The novel coronavirus SARS-CoV-2 is transmitted through species barriers from bats to humans [11]. COVID-19 is characterized by influenza-like symptoms ranging from mild to severe lung injury and multi-organ failure, leading to death in patients with comorbidities [12]. This novel virus has led to a global pandemic, resulting in unparalleled public health emergencies [13]. As of 10 March 2021, it has rapidly spread to 223 countries and territories, affecting over 117.3 million people and causing more than 2.6 million deaths [14].

The rapid and widespread emergence of SARS-CoV-2 indicates the urgent need for antiviral countermeasures. Currently, there are no available therapeutics against human coronaviruses. Various antivirals are currently being repositioned using clinical trials: nucleoside analogues (remdesivir, favipiravir, and ribavirin), protease inhibitors (disulfiram, lopinavir, and ritonavir), antiparasitic drugs (chloroquine and hydrochloroquine), pegylated interferons, monoclonal antibodies, oligonucleotide-based therapies, peptides, and small-molecule drugs are being contemplated as possible therapeutic agents against SARS-CoV-2 $[15,16]$. In particular, remdesivir, which inhibits viral RNA polymerases, is proposed as a potent antiviral against SARS-CoV-2 and clinical improvements have been observed in patients under compassionate use [4,17].

A 27-kDa recombinant antibody fragment, 3D8 is a single-chain variable fragment $(\mathrm{scFv})$ that comprises a variable region of a heavy chain covalently linked to the corresponding variable region of a light chain. The protein was originally found in autoimmuneprone Murphy Roths Large (MRL) mice [18]. The 3D8 scFv, which exerts the nucleic acid hydrolyzing-activity, degrades viral DNA and/or mRNA in the infected cells [19-21]. This protein elicited broad-spectrum antiviral effects against classical swine fever virus [20], influenza virus [22], herpes simplex virus (HSV), and pseudorabies virus (PRV) [23] in vitro. In addition, 3D8 exhibited in vivo antiviral therapeutic effects against PRV in C57BL/6 mice [24]. The transmission of avian influenza and bronchitis viruses was suppressed in transgenic chickens expressing 3D8 scFv [25,26]. However, the antiviral activity of 3D8 $\mathrm{scFv}$ against $\mathrm{SARS}-\mathrm{CoV}-2$ and other coronaviruses remains unknown.

Here, we aimed to investigate the antiviral activity of 3D8 scFv against emerging coronaviruses in vitro. These data provide insight into a broad-spectrum antiviral agent against SARS-CoV-2 and multiple coronaviruses.

\section{Materials and Methods}

\subsection{Ethics}

Antiviral study of 3D8 scFv against SARS-CoV-2 was performed at the Biosafety Level-3 Facilities at Hallym Clinical and Translational Science Institute, Hallym University, Chuncheon, South Korea under guidelines and protocols that were in line with institutional biosafety requirements (Hallym2020-04, 30 ${ }^{\text {th }}$, Oct., 2020, Hallym University Institutional Biosafety Committee). Experiments involving HCoV-OC43 and PEDV were performed at biosafety level 2. 


\subsection{Cells, Viruses, and $3 D 8 s c F v$}

African green monkey kidney epithelial Vero cells (ATCC ${ }^{\circledR}$ CCL-81) and Vero E6 cells (ATCC ${ }^{\circledR}$ CRL-1586) were maintained in Dulbecco's modified Eagle's medium (12-604F, Lonza, BioWhittaker ${ }^{\circledR}$, Walkersville, MD, USA) supplemented with $10 \%$ fetal bovine serum (FBS, Gibco, Life Technologies, Grand Island, NY, USA), $1 \% 10$ mM HEPES in $0.85 \% \mathrm{NaCl}$ (17-737E, Lonza, BioWhittaker ${ }^{\circledR}$, Walkersville, MD, USA), and $100 \mathrm{U} / \mathrm{mL}$ penicillin-100 $\mu \mathrm{g} / \mathrm{mL}$ streptomycin (15140-122, Gibco, Life Technologies, Grand Island, NY, USA). Cell cultures were maintained at $37^{\circ} \mathrm{C}$ under a $5 \% \mathrm{CO}_{2}$ atmosphere. Severe acute respiratory syndrome coronavirus-2 [SARS-CoV-2 (NCCP No. 43326)] was obtained from the National Culture Collection for Pathogens (Osong, Korea). Human coronavirus OC43 [HCoVOC43 (KBPV-VR-8)] and porcine epidemic diarrhea virus [PEDV (CV777)] were obtained from Korea Bank for Pathogenic Viruses (Seoul, Korea) and the Korean Animal and Plant Quarantine Agency (Kimcheon, Korea), respectively. The viruses were propagated in Vero E6 cells, and the infectious virus titer was determined using plaque assay. Finally, 3D8 scFv, a recombinant antibody molecule, was kindly provided by Novelgen. Detailed information regarding the queries and requests for $3 \mathrm{D} 8 \mathrm{scFv}$ can be obtained from Novelgen (thkim@novelgen.co.kr).

\subsection{In Vitro Transcription}

To determine whether the virus gene is directly degraded by 3D8, virus genes were amplified using PCR, and in vitro transcription and abzyme assays were performed. cDNA was synthesized from $0.5 \mu \mathrm{g}$ total RNA using random hexamers and MMLV reverse transcriptase (SuperScript IV Reverse Transcriptase, Thermo Fisher Scientific, Life Technologies, Carlsbad, CA, USA). PCR amplifications were performed in $20 \mu \mathrm{L}$ reaction mixtures containing $10 \mu \mathrm{L} 2 \times$ PCR premix (K-2018-1, AccuPower ${ }^{\circledR}$, Bioneer, Oakland, USA), $1 \mu \mathrm{L}$ forward primer ( $1 \mathrm{pmol}), 1 \mu \mathrm{L}$ reverse primer $(1 \mathrm{pmol})$, and $1 \mu \mathrm{g}$ cDNA. All virus-specific primers were designed using the Primer 3 program (Table S1). The PCR program was initiated with one cycle at $95^{\circ} \mathrm{C}$ for $2 \mathrm{~min}$, followed by 30 cycles at $95^{\circ} \mathrm{C}$ for $30 \mathrm{~s}, 45^{\circ} \mathrm{C}$ for $30 \mathrm{~s}$, and $72{ }^{\circ} \mathrm{C}$ for $90 \mathrm{~s}$, and a final cycle at $72{ }^{\circ} \mathrm{C}$ for $5 \mathrm{~min}$. Virus-specific PCR products were cloned into a pGEM-T Easy Vector (A1360, Promega Co., Madison, WI, USA) and used to transform E. coli DH5a cells. In vitro transcription was reacted for $2 \mathrm{~h}$ at $37^{\circ} \mathrm{C}$ using $2 \mu \mathrm{L}$ T7 RNA polymerase mix, $10 \mathrm{mM}$ of each dNTP, $1 \mu \mathrm{g}$ template, and $2 \mu \mathrm{L} 10 \times$ buffer (mixture of $1 \mathrm{M}$ Tris $\mathrm{HCl}, 20 \mathrm{mM} \mathrm{MgCl} 2,1 \mathrm{mM}$ Dithiothreitol and $\mathrm{H}_{2} \mathrm{O}$ ). The synthesized viral RNA fragments were reacted with 3D8 and $1 x$ reaction buffer $(1 \times \mathrm{TBS}, 10 \mathrm{mM} \mathrm{MgCl} 2)$ and confirmed using electrophoresis.

\subsection{Plaque Assay}

Vero E6 cells were seeded at $1 \times 10^{6}$ cells per well in 6-well plates (Falcon ${ }^{\mathrm{TM}} 353046$, Corning ${ }^{\circledR}$ NY, USA) and cultured at $37^{\circ} \mathrm{C}$ in a $\mathrm{CO}_{2}$ incubator. Cells were washed with phosphate buffer saline (PBS, Lonza, USA, BioWhittaker ${ }^{\circledR}$ ) and infected with ten-fold serial dilutions of virus suspension made in serum-free maintenance media (DMEM only) and incubated at $37^{\circ} \mathrm{C}$. After the infection for $1 \mathrm{~h}$ with intermittent shaking at $15 \mathrm{~min}$ intervals, virus inoculum was aspirated and replenished with $3 \mathrm{~mL}$ of overlay media (DMEM/F12 media) containing $0.6 \%$ oxoid agar and incubated at $37^{\circ} \mathrm{C}$ for 4 days. The plates were then fixed with 4\% paraformaldehyde (F1119Z21 YR, Biosesang, Seongnam-si, ROK). Overlay agar media was flicked and the plates were stained with crystal violet $(0.1 \%$ crystal violet in $20 \%$ methanol) for $30 \mathrm{~min}$. Plaques were enumerated, and the virus titers were quantified.

\subsection{In Vitro Antiviral Activity}

Vero E6 cells were seeded $\left(1 \times 10^{6}\right.$ cells per well) in 6-well plates $\left(\right.$ Corning $\left.{ }^{\circledR}\right)$ and incubated overnight at $37^{\circ} \mathrm{C}$ in a $\mathrm{CO}_{2}$ incubator. The cells were washed twice with PBS, and infected with viruses at different multiplicities of infectivity (MOI) for $2 \mathrm{~h}$ at $37^{\circ} \mathrm{C}$. The plates were manually rocked to ensure uniform and efficient distribution of the inoculum every 15-20 min. After adsorption, cells were treated with 3D8 at various concentrations. 
In the case of prophylactic treatment, Vero E6 cells were treated with 3D8 and incubated overnight before the virus challenge. Thereafter, supernatants and cells were harvested $48 \mathrm{~h}$ post-infection (hpi). The samples were stored at $-80^{\circ} \mathrm{C}$ until use.

\subsection{Real-Time Quantitative Polymerase Chain Reaction}

Total RNA was extracted using TRIzol (15596026, Ambion, Life Technologies, Carlsbad, CA, USA). Reverse transcription of RNA into cDNA was performed using a High Capacity RNA-to-cDNA kit (4387406, Thermo Fisher Scientific Baltics UAB, Vilnius, Lithuania) according to the manufacturer's protocol. Briefly, $1 \mu \mathrm{g}$ of RNA was used and cDNA was synthesized by an oligo deoxythymine $(\mathrm{dT})$ kit. The reaction was performed at $37^{\circ} \mathrm{C}$ for $60 \mathrm{~min}$ followed by $95^{\circ} \mathrm{C}$ for $5 \mathrm{~min}$.

Viral RNA was quantified using the Power SYBR ${ }^{\circledR}$ Green PCR Master Mix (4367659, Applied Biosystems ${ }^{\mathrm{TM}}$, Life Technologies Ltd., Woolston Warrington, UK) and primers for SARS-CoV-2 and other coronaviruses, with GAPDH as an endogenous control. Details of primers are listed in Table S2.

\subsection{Cell Viability Assay}

Vero E6 cells were seeded $\left(4 \times 10^{4}\right.$ cells per well) in 96-well plates (Corning $\left.{ }^{\circledR}\right)$ and incubated for $24 \mathrm{~h}$ at $37{ }^{\circ} \mathrm{C}$ in a $5 \% \mathrm{CO}_{2}$ atmosphere. Then, 3D8 was applied at various concentrations $(1 \mu \mathrm{M}$ to $40 \mu \mathrm{M})$ and the cells were incubated for $48 \mathrm{~h}$ at $37^{\circ} \mathrm{C}$. MTT solution (Intron, $10 \mu \mathrm{L}$ ) was added to each well, and the cells were incubated at $37^{\circ} \mathrm{C}$ for $3 \mathrm{~h}$. Thereafter, DMSO $(100 \mu \mathrm{L})$ was added and cellular viability was measured at $595 \mathrm{~nm}$.

\subsection{Immunoblot Assays}

Cells were lysed using RIPA lysis buffer (SC-24948, Santa Cruz Biotechnology, Texas, USA). Cell lysates were subjected to $10 \%$ sodium dodecyl sulfate-polyacrylamide gel electrophoresis (SDS-PAGE) and transferred to a nitrocellulose membrane using a wet method. After transmembrane transfer, it was incubated with primary antibodies-antiSARS-CoV-2 (PA1-41098, Invitrogen, Thermo Fisher Scientific, Massachusetts, USA), antiPEDV (9191, Median Diagnostics, Chuncheon-si, ROK), anti-HCoV-OC43(LS-C79764, LSbio, Seattle, WA, USA), and anti-human GAPDH antibody (ab9485, Abcam, Cambridge, UK) - overnight at $4{ }^{\circ} \mathrm{C}$ and then incubated with rabbit IgG-HRP conjugate (309-035-003, Jackson ImmunoResearch, West Grove, PA, USA) for $1 \mathrm{~h}$ at $37^{\circ} \mathrm{C}$. The membrane reaction with Enhanced chemiluminescence (ECL) solution (W3652-050, GenDEPOT, DAWINBio, Hanam, ROK) was observed and confirmed in chemiluminescence mode using ImageQuant LAS 500(GE).

\subsection{Immunocytochemistry}

Vero E6 cells were seeded $\left(1.5 \times 10^{4}\right.$ cells $)$ in an 8 -well chamber and incubated for $24 \mathrm{~h}$. PEDV and HCoV-OC43 were infected at an MOI of 0.002 and 0.2 , respectively, for $2 \mathrm{~h}$. Approximately $5 \mu \mathrm{M}(185 \mu \mathrm{g} / \mathrm{mL})$ purified 3D8 and 1\% Pen/Strep antibiotic were added to DMEM supplemented with $10 \%$ FBS and incubated at $37^{\circ} \mathrm{C}$ in a $5 \% \mathrm{CO}_{2}$ incubator. The cells were washed with PBS and fixed for $15 \mathrm{~min}$ in ice-cold methanol at room temperature. The cells were permeabilized with permeabilization buffer (421002, Biolegend $^{\circledR}$, San Diego, CA) for 10 min at room temperature. After blocking with $1 \%$ BSA and $0.3 \mathrm{M}$ (22.52 $\mathrm{mg} / \mathrm{mL})$ glycine in PBST buffer for $1 \mathrm{~h}$ at room temperature, primary antibodies for detecting PEDV (mouse anti-PEDV monoclonal Ab, MBS313516, Mybio), HCoV-OC43 (mouse anti-OC43 monoclonal Ab, LS-C79764, LS-bio), and 3D8 (polyclonal rabbit IgG serum $\mathrm{Ab}$ ) were incubated overnight at $4{ }^{\circ} \mathrm{C}$. PEDV and HCoV-OC43 were incubated with TRITC-conjugated anti-mouse Ab (ab6786, Abcam) and 3D8 was incubated with Alexa 488-conjugated anti-rabbit Ab (ab150077, Abcam). The nuclei were stained with Hoechst (62249, Thermo Fisher Scientific Inc., Rockford, IL, USA) during the last 10 min of incubation at RT. Cells were mounted in mounting medium (H-1200 Vectashield, Vector 
Laboratories, Burlingame, CA, USA) and observed with a NIKON A1R (Eclipse A1Rsi and Eclipse Ti-E).

\subsection{Statistical Analysis}

Statistical analyses of data were performed using Graph Pad Prism 8. Values are expressed in graph bars as mean \pm SD of at least three independent experiments and a $p$-value $<0.05$ was considered statistically significant.

\section{Results}

3.1. D8 Degraded In Vitro RNA Transcripts (IVTs) of SARS-CoV-2, HCoV-OC43, and PEDV

To investigate the direct nucleic acid-hydrolyzing activity of scFv, in vitro RNA transcripts (IVTs) of SARS-CoV-2, HCoV-OC43, and PEDV were treated with 3D8. It was found that 3D8 degraded the viral RNA IVTs in a time-dependent manner. Hydrolysis of SARS-CoV-2 and HCoV-OC43 IVTs was evident after treatment with 3D8 for $15 \mathrm{~min}$ (Figure 1A,B). Degradation of PEDV IVTs was observed after treatment with 3D8 for $30 \mathrm{~min}$ (Figure 1C). These data demonstrate the direct RNA-hydrolyzing activity of 3D8 against in vitro transcripts.

A

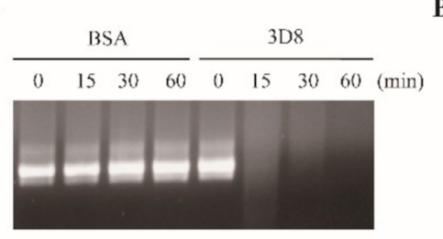

B

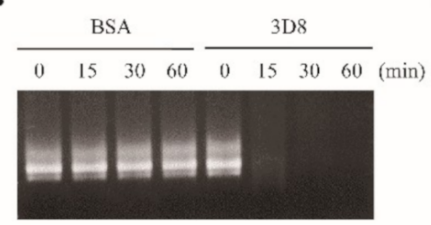

C

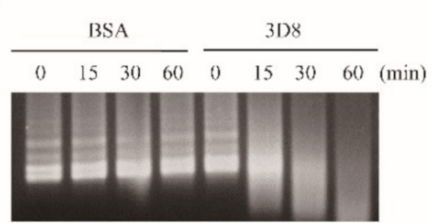

Figure 1. RNA-hydrolyzing activity of 3D8 for in vitro transcripts of severe acute respiratory syndrome coronavirus-2 (SARS-CoV-2), human coronavirus OC43 (HCoV-OC43), and porcine epidemic diarrhea virus (PEDV). (A) Nuclease activity of 3D8 against SARS-CoV-2. In vitro transcripts of SARS-CoV-2 were prepared and treated with 3D8. (B) Nuclease activity of 3D8 against $\mathrm{HCoV}-\mathrm{OC} 43$. In vitro transcripts of $\mathrm{HCoV}-\mathrm{OC} 43$ were prepared and treated with 3D8. (C) Nuclease activity of 3D8 against PEDV. In vitro transcripts of PEDV were prepared and treated with 3D8. Hydrolysis activity was determined by electrophoresis and observed under UV transilluminator.

\subsection{D8 Inhibited SARS-CoV-2 in a Dose-Dependent Manner}

To determine the antiviral activity of 3D8 against SARS-CoV-2 (MOI of 0.01), various concentrations of $\mathrm{scFv}$ were applied to Vero E6 cells after virus challenge. SARS-CoV-2 replication in cultures treated with various doses of 3D8 was quantified using RT-qPCR (Figure 2A). The replication of SARS-CoV-2 significantly decreased in a 3D8 dose-dependent manner. The $10 \mu \mathrm{M}$ and $5 \mu \mathrm{M}$ concentrations of 3D8 effectively inhibited viral replication by up to approximately $90 \%$ and $75 \%$, respectively, compared to the non-treatment group. Infectious virus particle production was quantified using the plaque assay (Figure 2B). The viral titer of SARS-CoV-2 was reduced in a 3D8 dose-dependent manner. In particular, when treated with $10 \mu \mathrm{M}$ 3D8, the infectious particles of SARS-CoV-2 were reduced by 10 times compared to the non-treatment group. Continual treatment with 3D8 showed antiviral activity against SARS-CoV-2 at an effective concentration $\left(\mathrm{EC}_{50}\right)$ of $4.25 \mu \mathrm{M}$ (Figure 2C). Moreover, this scFv did not show cytotoxicity in Vero E6 cells treated with 3D8 scFv at concentrations ranging from $1 \mu \mathrm{M}$ to $10 \mu \mathrm{M}$ (Figure 2D). However, cytotoxicity was observed at $40 \mu \mathrm{M}$, as reported in Jang et al., 2009. 
A

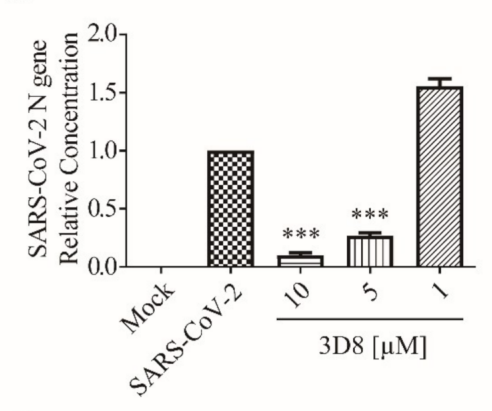

C

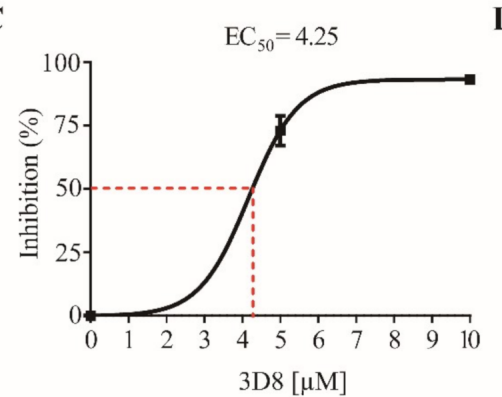

B

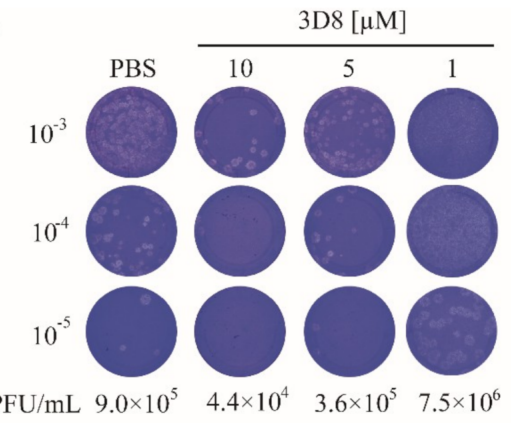

D

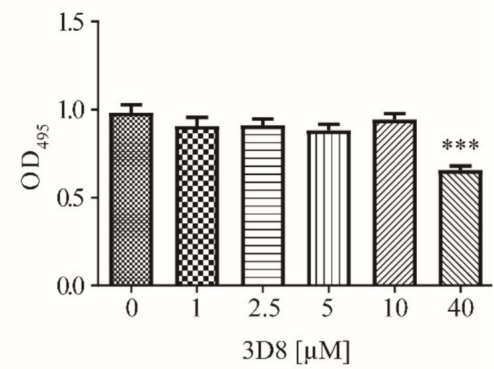

Figure 2. Antiviral activity of 3D8 scFv against severe acute respiratory syndrome coronavirus-2 (SARS-CoV-2) in a dose-dependent manner and a cytotoxicity assay. (A) Dose-dependent inhibition of SARS-CoV-2 by 3D8. Vero E6 cells were infected with SARS-CoV-2 at $2 \mathrm{hpi}$ and treated with a range of 3D8 concentrations for 48 hrs. The cells were harvested, and the viral RNA load was determined using RT-qPCR. (B) Supernatants from the 3D8-treated samples were collected, and a plaque assay was performed to determine the infectious viral titer. (C) Percent inhibition of SARSCoV-2 replication was shown by 3D8 in Vero E6 cells. Replication was measured via quantification of the viral RNA level. (D) Cytotoxicity testing of 3D8 in Vero E6 cells was performed by applying a range of various concentrations in uninfected cell cultures. Data presented here are representative of at least three independent experiments performed in triplicate. Error bars indicate the standard deviation of measurements in the representative experiment. ${ }^{* * *} p<0.001$, one-way ANOVA test; ns: non-significant.

\subsection{D8 Effectively Inhibited SARS-CoV-2 in Pretreated Cells (Prophylactic Effect)}

We determined the prophylactic antiviral activity of 3D8 scFv against SARS-CoV-2 (MOI of 0.01) in vitro. A significant reduction in the SARS-CoV-2 N gene copies was observed upon 2-h pretreatment with $10 \mu \mathrm{M}$ 3D8 scFv (Figure 3A). The N protein of SARS-CoV-2 was not observed from the pretreatment of 3D8 scFv prior to virus challenge (Figure 3B). Furthermore, we determined the inhibitory effect of pretreated 3D8 on the production of SARS-CoV-2 infectious particles. The production of infectious virus particles was more than 10 times lower in the $\mathrm{scFv}$ pretreated group than the control group (Figure 3C). Collectively, these data demonstrate that 3D8 has a prophylactic effect on SARS-CoV-2 infection. 
A
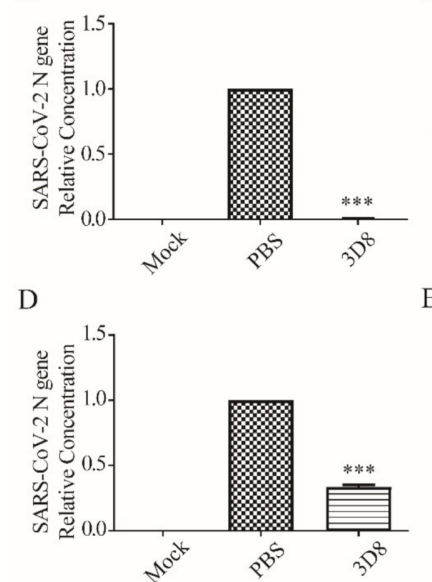

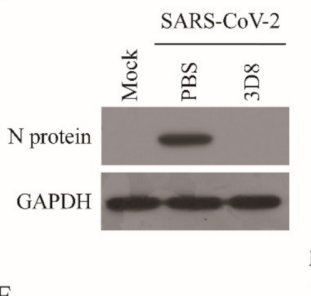

$\mathrm{C}$

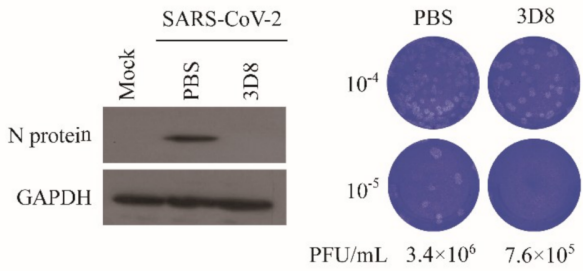

Figure 3. Prophylactic and therapeutic antiviral effects of 3D8 against severe acute respiratory syndrome coronavirus-2 (SARS-CoV-2). (A) Inhibition of SARS-CoV-2 by 3D8 in pretreated cell cultures. Vero E6 cells pretreated with 3D8 were infected with SARS-CoV-2. At $48 \mathrm{hpi}$, the cells were harvested, and the viral copy number was quantified based on the relative concentration of the $\mathrm{N}$ gene. (B) The N protein of SARS-CoV-2 was identified by Western blot. (C) Supernatants were harvested from 3D8-pretreated cell cultures infected with SARS-CoV-2, and the infectious viral titer was determined using a plaque assay. The clear zone indicates the plaque formation. (D) Inhibition of SARS-CoV-2 by 3D8 in post-treated cell cultures. Vero E6 cells were infected with SARS-CoV-2 at $2 \mathrm{hpi}$ and treated with 3D8 for $48 \mathrm{hrs}$. The cells were harvested, and the viral copy number was quantified based on the relative concentration of the $\mathrm{N}$ gene. (E) The N protein of SARS-CoV-2 was identified by Western blot. (F) Supernatants were harvested from 3D8-post-treated cell cultures infected with SARS-CoV-2, and the infectious viral titer was determined using a plaque assay. Data presented here are representative of at least three independent experiments performed in triplicate. *** $p<0.001$, one-way ANOVA test; ns: non-significant.

\subsection{D8 Effectively Inhibited SARS-CoV-2 in Post-Treated Cells (Therapeutic Effect)}

To determine the therapeutic effect, we assessed the inhibitory activity of 3D8 scFv on SARS-CoV-2 strain 2 hpi (Figure 3D). Firstly, 3D8 scFv decreased the gene copy number of the $\mathrm{N}$ gene. Western blot analysis revealed the absence of $\mathrm{N}$ protein expression in the 3D8-treated samples (Figure 3E). The production of infectious SARS-CoV-2 particles in the 3D8-treated group was 10 times lower than that in the control group (Figure 3F). The reduction in viral gene copy number, $\mathrm{N}$ protein expression, and infectious virus particles indicated the therapeutic effect of 3D8 on SARS-CoV-2 infection.

\subsection{D8 Possesses Broad-Spectrum Antiviral Activity against Multiple Coronaviruses}

To explore the antiviral activity of 3D8 against other coronaviruses, viral gene copies and infectious particles were examined after HCoV-OC43 and PEDV infections. The 3D8treated group showed effective inhibition of viral replication upon HCoV-OC43 infection. The load of HCoV-OC43 RNA was significantly reduced in a 3D8 dose-dependent manner (Figure 4A). The expression of viral proteins was inhibited in the presence of 3D8 (Figure 4B). Moreover, 3D8 effectively inhibited the replication of HCoV-OC43, with an $\mathrm{EC}_{50}$ value of $1.40 \mu \mathrm{M}$ (Figure $4 \mathrm{C}$ ). Immunohistochemistry analysis revealed a reduction in HCoV-OC43 replication upon 3D8 treatment (Figure 4D).

Treatment with 3D8 resulted in the effective inhibition of viral replication during PEDV infection. The PEDV RNA load was significantly suppressed in a 3D8 dose-dependent manner (Figure 5A). The expression of viral proteins was reduced upon treatment with 3D8 (Figure 5B). The $\mathrm{EC}_{50}$ value of 3D8 was $1.10 \mu \mathrm{M}$ against PEDV (Figure 5C). Immunohistochemistry analysis revealed a reduction in PEDV replication upon 3D8 treatment (Figure 5D). These data demonstrated the broad-spectrum activity of 3D8 against multiple zoonotic coronaviruses. 
A

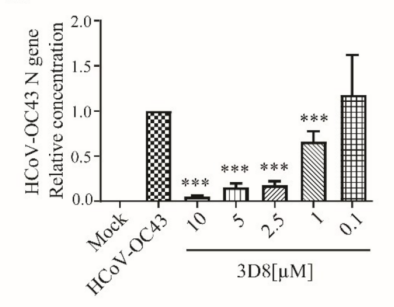

C

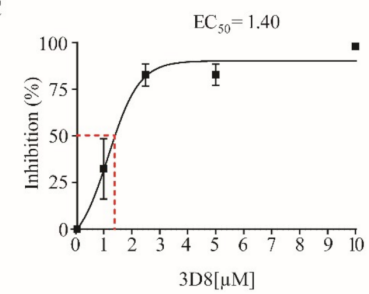

B
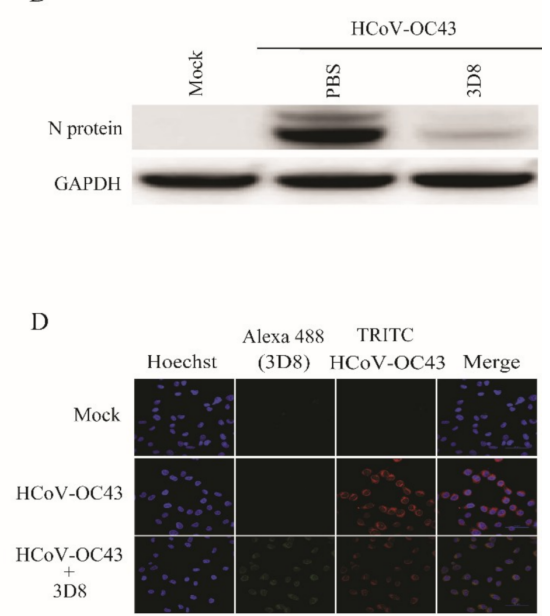

Figure 4. In vitro antiviral effect of 3D8 against human coronavirus OC43 (HCoV-OC43). (A) Dosedependent inhibition of HCoV-OC43 by 3D8. Vero E6 cells were infected with HCoV-OC43 at 2 hpi and treated with a range of 3D8 concentrations for $48 \mathrm{hrs}$. The cells were harvested, and the virus copy number was determined using qPCR. (B) The N protein of HCoV-OC43 was identified by Western blot. (C) Percent inhibition of HCoV-OC43 replication was shown by 3D8 in Vero E6 cells. Replication was measured via quantification of the viral RNA level. (D) At $48 \mathrm{hpi}$, the cells were washed with PBS and fixed using methanol. Then, they were permeabilized with buffer and blocked with BSA. The cells were then incubated with primary antibodies overnight. After incubation, TRITC-conjugated anti-mouse and Alexa 488-conjugated anti-rabbit antibodies were added. Hoechst was used to stain the nucleus. Data presented here are representative of at least three independent experiments performed in triplicate. ${ }^{* * *} p<0.001$; one-way ANOVA test; ns: non-significant.

A

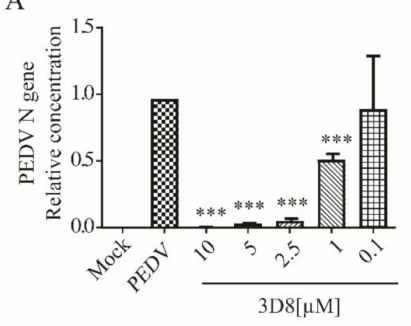

$\mathrm{C}$

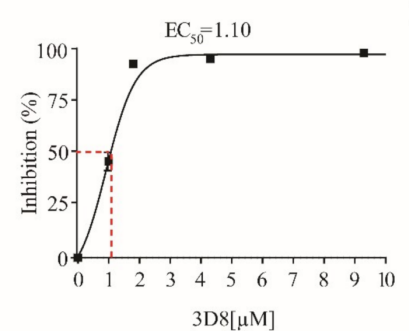

B
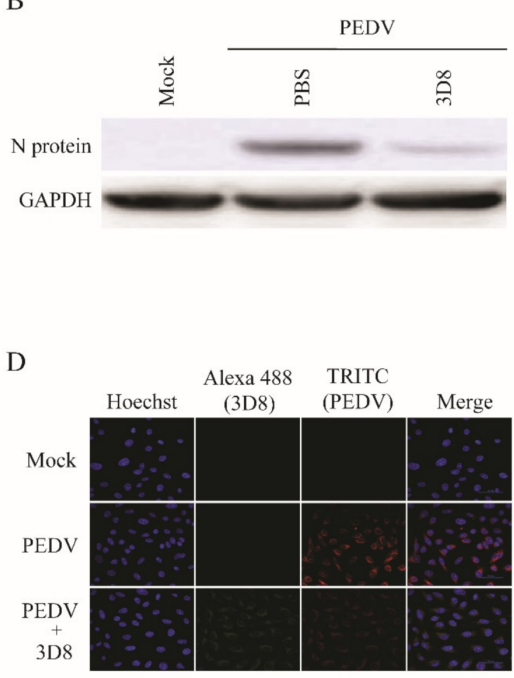

Figure 5. In vitro antiviral effect of different concentrations of 3D8 against porcine epidemic diarrhea virus (PEDV). (A) Dose-dependent inhibition of PEDV by 3D8. Vero E6 cells were infected with PEDV at $2 \mathrm{hpi}$ and treated with a range of 3D8 concentrations for $48 \mathrm{hrs}$. The cells were harvested, and the viral RNA load was determined using qPCR. (B) The N protein of PEDV was identified by Western blot. (C) Percent inhibition of PEDV replication was shown by 3D8 in Vero E6 cells. Replication was measured via quantification of the viral RNA level. (D) At 48 hpi, the cells were washed with PBS and fixed with methanol. Then, they were permeabilized with buffer and blocked with BSA. The cells were incubated with primary antibodies overnight. After incubation, TRITC-conjugated anti-mouse and Alexa 488-conjugated anti-rabbit antibodies were added. Hoechst was used to stain the nucleus. Data presented here are representative of at least three independent experiments performed in triplicate. ${ }^{* *} p<0.001$; one-way ANOVA test; ns: non-significant. 


\section{Discussion}

Novel human coronaviruses have emerged during the past two decades [3,27]. The COVID-19 outbreak occurred in late December in Wuhan (China) and rapidly became a global pandemic [6]. The public health emergency caused by the SARS-CoV-2 outbreak has led to a demand for countermeasures against emerging and re-emerging zoonotic coronaviruses. As the virus disseminates, efforts are being made to mitigate transmission via public health interventions including social distancing, case isolation (quarantine), and contact tracing. However, therapeutics and vaccines against SARS-CoV-2 are urgently needed for the effective control of outbreaks. In this study, we demonstrated that 3D8, a nucleic acid-hydrolyzing scFv, inhibited the replication of SARS-CoV-2 and multiple coronaviruses in vitro.

$\mathrm{scFv}$ is a molecule derived from an antibody composed of variable regions of heavy and light chains linked with peptides [18]. This protein has been utilized for biotechnological and medicinal applications, such as in the treatment of infectious diseases, as a cancer therapy, and as a potential alternative to conventional diagnostic approaches $[28,29]$. The $\mathrm{scFv}$ has various advantages over traditional monoclonal antibodies, such as ease of genetic manipulation, rapid molecular design and characterization, greatly reduced size, production of antibodies against viral proteins, and various expression systems [29]. Neutralizing $\mathrm{scFv}$ against the $\mathrm{N}$ protein protected piglets from PEDV infection. The orally administered piglets exhibited either no clinical symptoms or mild symptoms and intestinal lesions, with significantly increased survival rates [30]. Moreover, 3D8, a unique scFv with broadspectrum nuclease activity, confers antiviral activities against a variety of viruses, including DNA and RNA viruses [23,24]. The 3D8 scFv showed antiviral effects against infectious bronchitis virus, a member of the gammacoronavirus family, in transgenic chickens [26]. However, the antiviral activity of $3 \mathrm{D} 8 \mathrm{scFv}$ against SARS-CoV-2 and other coronaviruses remains to be investigated.

Our study demonstrated that 3D8 conferred effective antiviral activity against SARSCoV-2, HCoV-OC43, and PEDV in vitro. It inhibited the replication of multiple coronaviruses in a dose-dependent manner. The nuclease activity of 3D8 contributed to the reduction of infectious virus particles, indicating that the degradation of viral nucleic acids prohibited the production of viral genomes and proteins (Figure 6). In addition, therapeutic treatment with 3D8 scFv inhibited the replication of SARS-CoV-2, HCoV-OC43, and PEDV, resulting in a lack of viral replication, infectious particle formation, and protein expression. Previous studies demonstrated the biochemical characteristics and robust antiviral activity of 3D8 scFv against classical swine fever virus and HSV in vitro [20,23]. Transgenic mouse and chicken were generated by expressing 3D8, demonstrating its in vivo antiviral activity against influenza virus and PRV [24,25]. The entry mechanism of 3D8 revealed a caveolindependent manner and easy penetration of the cell without a carrier [21]. Intranasal transfer of 3D8 scFv into a mouse penetrated well into the epithelial barrier of lung tissue [22]. In addition, 3D8 stably existed in the lung and various tissues of the inoculated mouse (not shown). Taken together, these findings suggest that 3D8, a nucleic-acid hydrolyzing mini-antibody, may be a potential antiviral candidate due to its broad-spectrum activity, easy penetration into the cell, and the accessibility to the lung in vivo.

Coronavirus infections have significantly impacted both humans and livestock [31]. However, effective antiviral countermeasures against these viruses are still unavailable. $\mathrm{HCoV-OC43,} \mathrm{which} \mathrm{belongs} \mathrm{to} \mathrm{the} \mathrm{lineage} \mathrm{betacoronaviruses,} \mathrm{is} \mathrm{associated} \mathrm{with} \mathrm{mild}$ common cold in humans. HCoV-OC43 infection occurs frequently in early childhood and causes acute respiratory tract illness, pneumonia, and croup [32]. PEDV, a member of the alphacoronavirus family, is a highly contagious coronavirus that causes severe diarrhea and death in neonatal piglets [30]. All age groups are highly susceptible to PEDV infection, with neonatal piglets under two weeks of age showing the highest mortality rates [30]. In this study, the administration of 3D8 also elicited a reduction in replication and protein synthesis of HCoV-OC43 and PEDV, followed by the formation of infectious particles. 
These results suggest that 3D8 may be a potential antiviral candidate for applications in humans and in livestock.

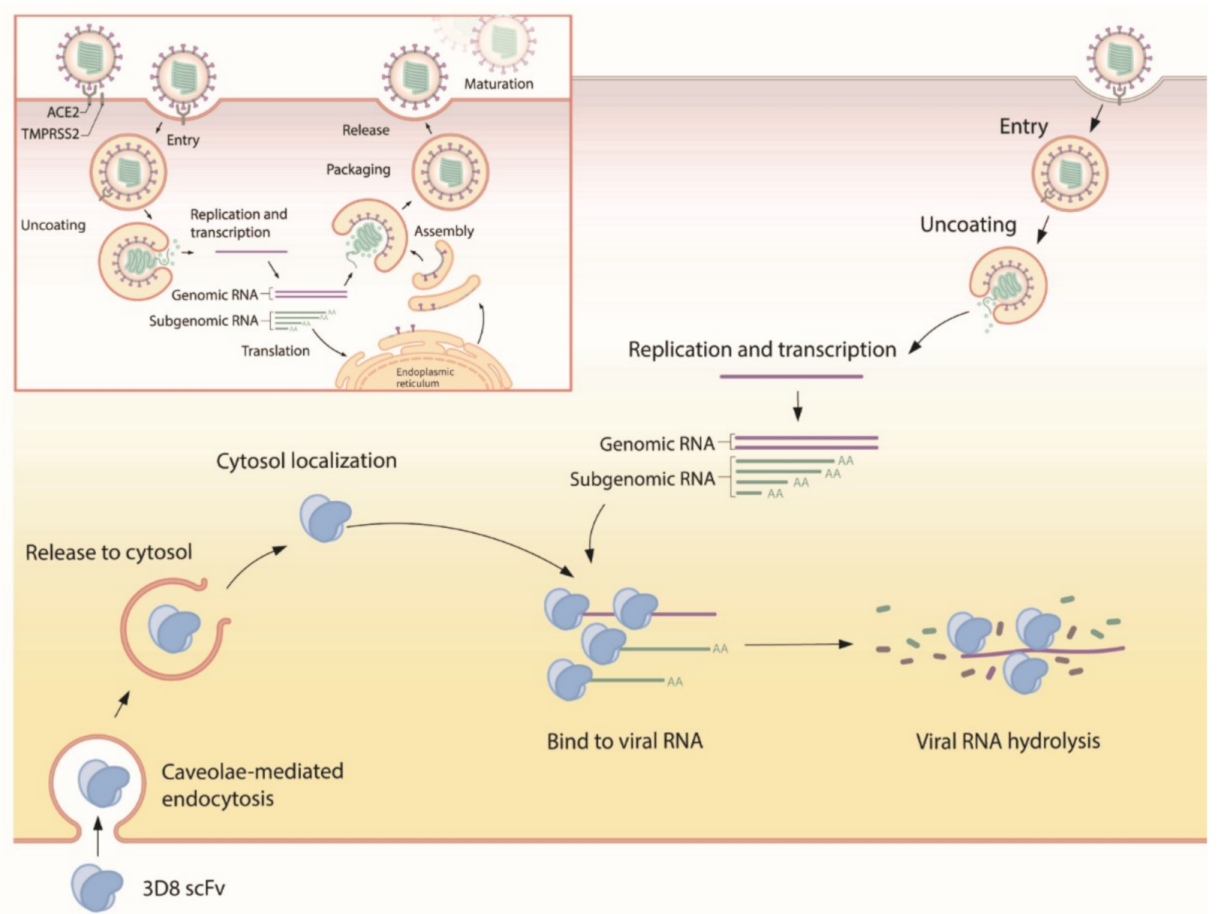

Figure 6. Suggested mode of action for 3D8. First, 3D8 scFv is internalized into the cell through caveolae-mediated endocytosis. After release from the endosomal compartment, 3D8 binds to the viral nucleic acid and degrades it to prevent its amplification, thus inhibiting viral growth. In addition, 3D8 exerts nuclease activity without sequence specificity and hydrolyzes viral RNA genomes or transcripts.

RNA viruses constantly undergo genetic mutation owing to the lack of proofreading activity of RdRp polymerases, resulting in the emergence of new variants of the virus over time [33]. A variant of SARS-CoV-2 with a D614G substitution on the spike protein was reported in February, 2020 [34]. This variant quickly became a dominant strain, circulating globally due to increased infectivity in humans [34,35]. Notably, the variants of SARSCoV-2 from the United Kingdom and the Republic of South Africa have raised significant concern [36]. The variant from the United Kingdom, referred to as SARS-CoV-2 (B.1.1.7), with 23 nucleotide substitutions, was a phylogenetic genotype distinct from the origin of SARS-CoV-2 strains [37]. Another variant from South Africa, referred to as SARS-CoV-2 (B.1.351), shared genetic similarity with SARS-CoV-2 B.1.1.7, but it belonged to a distinct phylogenetic lineage from B 1.1.7 [34,36]. The genetic variation of SARS-CoV-2 may impact the effectiveness and efficacy of antivirals or vaccines targeting viral proteins, since genetic mutation facilitates the evasion of antiviral molecular mechanisms and humoral responses. In this study, in vitro RNA transcripts of SARS-CoV-2, HCoV-OC43, and PEDV were degraded by $3 \mathrm{D} 8 \mathrm{scFv}$ in a sequence-independent manner. In addition, administration of 3D8 elicited the degradation of viral RNA upon infection with several Influenza virus strains, including H1N1, H9N2, and oseltamivir-resistant H1N1 [22,25,38]. Thus, 3D8 scFv possesses broad-spectrum nucleic acid-hydrolyzing activity, indicating that this protein may exert antiviral activity against variants of SARS-CoV-2.

Our study demonstrated that 3D8 scFv effectively inhibited SARS-CoV-2 and multiple coronaviruses (HCoV-OC43 and PEDV) in vitro. However, the absence of in vivo studies in animal models is a major limitation. To address this issue, further studies are needed to illustrate the in vivo inhibitory effect of 3D8 scFv in hACE2-transgenic mice, hamsters, ferrets, or non-human primate models. Remdesivir conferred promising antiviral activity against SARS-CoV-2 in hACE2-transgenic mice [4,39] and rhesus macaques [40]. A combi- 
nation therapy of remdesivir with methylprednisolone showed beneficial effects against SARs-CoV-2 in hamsters [41]. A ribonucleoside analogue MK-4482/EIDD-2801 inhibited SARS-CoV-2 transmission in ferrets [42] and FDA-approved antivirals marginally reduced viral loads in SARS-CoV-2-infected ferrets [43]. Transgenic hACE-2 mice are a representative animal model for SARS-CoV-2 due to the presence of appropriate receptors to initiate infection [44]. This hACE2-transgenic model can be employed for the in vivo study of 3D8 against SARS-CoV-2. Administration of scFv in hamsters, ferrets, and non-human primates can be a potential alternative to elicit the in vivo antiviral activity of 3D8 against SARS-CoV-2 and other zoonotic viruses.

The extensive antiviral activities of 3D8 demonstrated nucleic acid-hydrolyzing degradation on a variety of viruses, such as plant viruses as well as animal viruses [20,22,24,25,45,46]. In contrast, porcine $\mathrm{scFv}$ showed antiviral effects by neutralizing infectious virus particles [30]. Recently, a nano-body (Ty1) with a single heavy chain, lacking a light chain, exhibited antiviral activity against SARS-CoV-2 in vitro [47]. The nanobody bound to the receptor-binding domain of the SARS-CoV-2 spike protein and neutralized the infectious particles. However, the viral neutralizing activity of 3D8 scFv has not been reported. The potential of antigen binding and neutralization of 3D8 scFv remains to be further explored.

In conclusion, 3D8 scFv confers broad-spectrum antiviral activity against SARS-CoV-2 and multiple coronaviruses in vitro. This study provides insights into the effective antiviral countermeasure of $\mathrm{scFv}$ against emerging viral outbreaks.

Supplementary Materials: The following are available online at https:/ / www.mdpi.com/article/10 $.3390 / v 13040650 /$ s1, Table S1: Primers used for in vitro transcription viral spike gene amplification, Table S2: Primers used for RT-qPCR of SARS-CoV-2, HCoV-OC43, and PEDV.

Author Contributions: Conceptualization, G.L., S.B., T.-H.K., J.-W.S., and W.-K.K.; Methodology, G.L., S.B., S.C. and W.-K.K. Conducted experiments; Investigation: G.L., S.B., G.-Y.L., K.-j.O., Y.K.H., Y-J.K., Y.R.L., P.T.H., Y.L., S.-W.L., J.-M.K., S.C. and W.-K.K; Visualization; G.L., S.B., G.-Y.L., S.C., S.L. and W.-K.K. Formal analysis, Data curation, G.L., S.B., Y.L., S.C. and W.-K.K.; Writing-original draft preparation, G.L., S.B., and W.-K.K. Writing-review and editing, S.C. and W.-K.K.; Project administration, G.L., S.B., S.L. and W.-K.K.; Funding acquisition, J.-W.S., S.L. and W.-K.K. All authors have read and agreed to the published version of the manuscript.

Funding: This work was supported by Novelgen (6R190101532S000100 and S-2018-1158-000) and the Research Program to Solve Social Issues of the National Research Foundation of Korea (NRF) funded by the Ministry of Science and ICT (NRF-2017M3A9E4061992).

Institutional Review Board Statement: Not applicable.

Informed Consent Statement: Not applicable.

Data Availability Statement: All the data generated for this publication have been included in the current manuscript.

Acknowledgments: We thank Jonghun Jeon (Hallym University) and Song-hee Han (Novelgen) for supporting the BL-3 facility and describing the figure, respectively.

Conflicts of Interest: The authors declare that the research was conducted in the absence of any commercial or financial relationships that could be construed as a potential conflict of interest.

\section{References}

1. Sun, S.H.; Chen, Q.; Gu, H.J.; Yang, G.; Wang, Y.X.; Huang, X.Y.; Liu, S.S.; Zhang, N.N.; Li, X.F.; Xiong, R.; et al. A Mouse Model of SARS-CoV-2 Infection and Pathogenesis. Cell Host Microbe 2020, 28, 124-133.e4. [CrossRef] [PubMed]

2. Fan, Y.; Zhao, K.; Shi, Z.L.; Zhou, P. Bat Coronaviruses in China. Viruses 2019, 11, 210. [CrossRef] [PubMed]

3. Timothy, P.; Sheahan, A.C.S.; Zhou, S.; Graham, R.L.; Pruijssers, A.J.; Agostini, M.L.; Leist, S.R.; Schäfer, A.; Dinnon, K.H., 3rd; Stevens, L.J.; et al. An orally bioavailable broad-spectrum antiviral inhibits SARS-CoV-2 in human airway epithelial cell cultures and multiple coronaviruses in mice. Sci. Transl. Med. 2020, 12, eabb5883.

4. Pruijssers, A.J.; George, A.S.; Schafer, A.; Leist, S.R.; Gralinksi, L.E.; Dinnon, K.H., 3rd; Yount, B.L.; Agostini, M.L.; Stevens, L.J.; Chappell, J.D.; et al. Remdesivir Inhibits SARS-CoV-2 in Human Lung Cells and Chimeric SARS-CoV Expressing the SARS-CoV-2 RNA Polymerase in Mice. Cell Rep. 2020, 32, 107940-107950. [CrossRef] 
5. Xie, X.; Muruato, A.; Lokugamage, K.G.; Narayanan, K.; Zhang, X.; Zou, J.; Liu, J.; Schindewolf, C.; Bopp, N.E.; Aguilar, P.V.; et al. An Infectious cDNA Clone of SARS-CoV-2. Cell Host Microbe 2020, 27, 841-848. [CrossRef]

6. Zhu, N.; Zhang, D.; Wang, W.; Li, X.; Yang, B.; Song, J.; Zhao, X.; Huang, B.; Shi, W.; Lu, R.; et al. A Novel Coronavirus from Patients with Pneumonia in China, 2019. N. Engl. J. Med. 2020, 382, 727-733. [CrossRef]

7. Harcourt, J.; Tamin, A.; Lu, X.; Kamili, S.; Sakthivel, S.K.; Murray, J.; Queen, K.; Tao, Y.; Paden, C.R.; Zhang, J.; et al. Severe Acute Respiratory Syndrome Coronavirus 2 from Patient with Coronavirus Disease, United States. Emerg. Infect. Dis. 2020, 26, 1266-1273. [CrossRef]

8. Lu, R.; Zhao, X.; Li, J.; Niu, P.; Yang, B.; Wu, H.; Wang, W.; Song, H.; Huang, B.; Zhu, N.; et al. Genomic characterisation and epidemiology of 2019 novel coronavirus: Implications for virus origins and receptor binding. Lancet 2020, 395, 565-574. [CrossRef]

9. Hoffmann, M.; Kleine-Weber, H.; Schroeder, S.; Kruger, N.; Herrler, T.; Erichsen, S.; Schiergens, T.S.; Herrler, G.; Wu, N.H.; Nitsche, A.; et al. SARS-CoV-2 Cell Entry Depends on ACE2 and TMPRSS2 and Is Blocked by a Clinically Proven Protease Inhibitor. Cell 2020, 181, 271-280. [CrossRef]

10. Chen, Z.; Zhang, W.; Lu, Y.; Guo, C.; Guo, Z.; Liao, C.; Zhang, X.; Zhang, Y.; Han, X.; Li, Q.; et al. From SARS-CoV to Wuhan 2019-nCoV Outbreak: Similarity of Early Epidemic and Prediction of Future Trends. Cell Host Microbe 2020. (in Press). [CrossRef]

11. Gorbalenya, A.E.; Baker, S.C.; Baric, R.S.; de Groot, R.J.; Drosten, C.; Gulyaeva, A.A.; Haagmans, B.L.; Lauber, C.; Leontovich, A.M.; Neuman, B.W.; et al. Severe acute respiratory syndrome-related coronavirus: The species and its viruses - a statement of the Coronavirus Study Group. Nature Microbiol. 2020, 5, 536-544.

12. Monteil, V.; Kwon, H.; Prado, P.; Hagelkruys, A.; Wimmer, R.A.; Stahl, M.; Leopoldi, A.; Garreta, E.; Hurtado Del Pozo, C.; Prosper, F; , et al. Inhibition of SARS-CoV-2 Infections in Engineered Human Tissues Using Clinical-Grade Soluble Human ACE2. Cell 2020, 181, 905-913. [CrossRef]

13. Gussow, A.B.; Auslander, N.; Faure, G.; Wolf, Y.I.; Zhang, F.; Koonin, E.V. Genomic determinants of pathogenicity in SARS-CoV-2 and other human coronaviruses. Proc. Natl. Acad. Sci. USA 2020, 117, 15193-15199. [CrossRef]

14. World Health Organization Coronavirus Disease(Covid-19) Pandemic. Available online: https://www.who.int/emergencies/ diseases/novel-coronavirus-2019 (accessed on 11 March 2011).

15. Li, G.; De Clercq, E. Therapeutic options for the 2019 novel coronavirus (2019-nCoV). Nat. Rev. Drug Discov. 2020, 19, 149-150. [CrossRef]

16. Rosa, S.G.V.; Santos, W.C. Clinical trials on drug repositioning for COVID-19 treatment. Rev. Panam. Salud. Publica. 2020, 44, e40. [CrossRef]

17. Wang, M.; Cao, R.; Zhang, L.; Yang, X.; Liu, J.; Xu, M.; Shi, Z.; Hu, Z.; Zhong, W.; Xiao, G. Remdesivir and chloroquine effectively inhibit the recently emerged novel coronavirus (2019-nCoV) in vitro. Cell Res. 2020, 30, 269-271. [CrossRef]

18. Kwon, M.H.; Lee, M.S.; Kim, K.H.; Park, S.; Shin, H.-J.; Jang, Y.-J.; Kim, H.-I. Production and Characterization of an anti-idiotypic single chain $\mathrm{fv}$ that recognizes an anti-DNA antibody. Immunol. Invest. 2002, 31, 205-218. [CrossRef]

19. Kim, Y.R.; Kim, J.S.; Lee, S.H.; Lee, W.R.; Sohn, J.N.; Chung, Y.C.; Shim, H.K.; Lee, S.C.; Kwon, M.H.; Kim, Y.S. Heavy and light chain variable single domains of an anti-DNA binding antibody hydrolyze both double- and single-stranded DNAs without sequence specificity. J. Biol. Chem. 2006, 281, 15287-15295. [CrossRef]

20. Jun, H.R.; Pham, C.D.; Lim, S.I.; Lee, S.C.; Kim, Y.S.; Park, S.; Kwon, M.H. An RNA-hydrolyzing recombinant antibody exhibits an antiviral activity against classical swine fever virus. Biochem. Biophys. Res. Commun. 2010, 395, 484-489. [CrossRef]

21. Jang, J.Y.; Jeong, J.G.; Jun, H.R.; Lee, S.C.; Kim, J.S.; Kim, Y.S.; Kwon, M.H. A nucleic acid-hydrolyzing antibody penetrates into cells via caveolae-mediated endocytosis, localizes in the cytosol and exhibits cytotoxicity. Cell Mol. Life Sci. 2009, 66, 1985-1997. [CrossRef]

22. Zhang, F.; Chen, Y.; Ke, Y.; Zhang, L.; Zhang, B.; Yang, L.; Zhu, J. Single Chain Fragment Variable (scFv) Antibodies Targeting the Spike Protein of Porcine Epidemic Diarrhea Virus Provide Protection against Viral Infection in Piglets. Viruses 2019, 11, 58. [CrossRef]

23. Cho, S.; Youn, H.N.; Hoang, P.M.; Cho, S.; Kim, K.E.; Kil, E.J.; Lee, G.; Cho, M.J.; Hong, J.; Byun, S.J.; et al. Preventive Activity against Influenza (H1N1) Virus by Intranasally Delivered RNA-Hydrolyzing Antibody in Respiratory Epithelial Cells of Mice. Viruses 2015, 7, 5133-5144. [CrossRef]

24. Lee, G.; Yu, J.; Cho, S.; Byun, S.J.; Kim, D.H.; Lee, T.K.; Kwon, M.H.; Lee, S. A nucleic-acid hydrolyzing single chain antibody confers resistance to DNA virus infection in hela cells and C57BL/ 6 mice. PLoS Pathog. 2014, 10, e1004208. [CrossRef]

25. Lee, G.; Cho, S.; Hoang, P.M.; Kim, D.; Lee, Y.; Kil, E.J.; Byun, S.J.; Lee, T.K.; Kim, D.H.; Kim, S.; et al. Therapeutic Strategy for the Prevention of Pseudorabies Virus Infection in C57BL/6 Mice by 3D8 scFv with Intrinsic Nuclease Activity. Mol. Cells 2015, 38, 773-780. [CrossRef]

26. June Byun, S.; Yuk, S.S.; Jang, Y.J.; Choi, H.; Jeon, M.H.; Erdene-Ochir, T.O.; Kwon, J.H.; Noh, J.Y.; Sun Kim, J.; Gyu Yoo, J.; et al. Transgenic Chickens Expressing the 3D8 Single Chain Variable Fragment Protein Suppress Avian Influenza Transmission. Sci. Rep. 2017, 7, 5938. [CrossRef]

27. Lee, G.; Choi, H.; Sureshkumar, S.; Jung, S.K.; Kim, J.S.; Oh, K.B.; Kim, K.W.; Yang, H.; Kim, D.H.; Byun, S.J. The 3D8 single chain variable fragment protein suppress infectious bronchitis virus transmission in the transgenic chickens. Res. Vet. Sci. 2019, 123, 293-297. [CrossRef]

28. Blanco-Melo, D.; Nilsson-Payant, B.E.; Liu, W.C.; Uhl, S.; Hoagland, D.; Moller, R.; Jordan, T.X.; Oishi, K.; Panis, M.; Sachs, D.; et al. Imbalanced Host Response to SARS-CoV-2 Drives Development of COVID-19. Cell 2020, 181, 1036-1045.e9. [CrossRef] 
29. Lee, J.; Park, H.; Kim, M.; Seo, Y.; Lee, Y.; Byun, S.J.; Lee, S.; Kwon, M.H. Functional stability of 3D8 scFv, a nucleic acidhydrolyzing single chain antibody, under different biochemical and physical conditions. Int. J. Pharm. 2015, 496, 561-570. [CrossRef]

30. Ahmad, Z.A.; Yeap, S.K.; Ali, A.M.; Ho, W.Y.; Alitheen, N.B.; Hamid, M. scFv antibody: Principles and clinical application. Clin. Dev. Immunol. 2012, 2012, 980250. [CrossRef]

31. Fields, B.N.; Knipe, D.M.; Howley, P.M.; Griffin, D.E. Fields' Virology; Wolters Kluwer Health/Lippincott Williams \& Wilkins: Philadelphia, PA, USA, 2007.

32. Dijkman, R.; Jebbink, M.F.; Gaunt, E.; Rossen, J.W.; Templeton, K.E.; Kuijpers, T.W.; van der Hoek, L. The dominance of human coronavirus OC43 and NL63 infections in infants. J. Clin. Virol. 2012, 53, 135-139. [CrossRef]

33. Smith, E.C. The not-so-infinite malleability of RNA viruses: Viral and cellular determinants of RNA virus mutation rates. PLoS Pathog. 2017, 13, e1006254. [CrossRef] [PubMed]

34. World Health Organization. SARS-CoV-2 Variants. Available online: https://www.who.int/csr/don/31-december-2020-sarscov2-variants/en/ (accessed on 20 February 2021).

35. Korber, B.; Fischer, W.M.; Gnanakaran, S.; Yoon, H.; Theiler, J.; Abfalterer, W.; Hengartner, N.; Giorgi, E.E.; Bhattacharya, T.; Foley, B.; et al. Tracking Changes in SARS-CoV-2 Spike: Evidence that D614G Increases Infectivity of the COVID-19 Virus. Cell 2020, 182, 812-827. [CrossRef] [PubMed]

36. CDC Emerging SARS-CoV-2 Variants. Available online: https://www.cdc.gov/coronavirus/2019-ncov/more/science-andresearch/scientific-brief-emerging-variants.html (accessed on 20 February 2021).

37. Lee, R.B. 1.1.7: What We Know About the Novel SARS-CoV-2 Variant. Available online: https://asm.org/Articles/2021/January/ B-1--1-7-What-We-Know-About-the-Novel-SARS-CoV-2-Variants (accessed on 20 February 2021).

38. Lee, Y.; Kim, D.; Kim, T.; Oh, Y.; Kim, W.-K.; Lee, S. Antiviral effect of a nucleic acid hydrolyzing scFv against oseltamivir resistant influenza A virus. Manuscript in preparation. BioRxiv 2021. [CrossRef]

39. Li, Y.; Cao, L.; Li, G.; Cong, F.; Li, Y.; Sun, J.; Luo, Y.; Chen, G.; Li, G.; Wang, P.; et al. Remdesivir Metabolite GS-441524 Effectively Inhibits SARS-CoV-2 Infection in Mouse Models. J. Med. Chem. 2021. [CrossRef]

40. Williamson, B.N.; Feldmann, F.; Schwarz, B.; Meade-White, K.; Porter, D.P.; Schulz, J.; van Doremalen, N.; Leighton, I.; Yinda, C.K.; Perez-Perez, L.; et al. Clinical benefit of remdesivir in rhesus macaques infected with SARS-CoV-2. Nature 2020, 585, 273-276. [CrossRef]

41. Ye, Z.W.; Yuan, S.; Chan, J.F.; Zhang, A.J.; Yu, C.Y.; Ong, C.P.; Yang, D.; Chan, C.C.; Tang, K.; Cao, J.; et al. Beneficial effect of combinational methylprednisolone and remdesivir in hamster model of SARS-CoV-2 infection. Emerg. Microbes Infect. 2021, 10, 291-304. [CrossRef]

42. Cox, R.M.; Wolf, J.D.; Plemper, R.K. Therapeutically administered ribonucleoside analogue MK-4482/EIDD-2801 blocks SARSCoV-2 transmission in ferrets. Nat. Microbiol. 2021, 6, 11-18. [CrossRef]

43. Park, S.J.; Yu, K.M.; Kim, Y.I.; Kim, S.M.; Kim, E.H.; Kim, S.G.; Kim, E.J.; Casel, M.A.B.; Rollon, R.; Jang, S.G.; et al. Antiviral Efficacies of FDA-Approved Drugs against SARS-CoV-2 Infection in Ferrets. mBio 2020, 11, 01114-01120. [CrossRef]

44. Munoz-Fontela, C.; Dowling, W.E.; Funnell, S.G.P.; Gsell, P.S.; Riveros-Balta, A.X.; Albrecht, R.A.; Andersen, H.; Baric, R.S.; Carroll, M.W.; Cavaleri, M.; et al. Animal models for COVID-19. Nature 2020, 586, 509-515. [CrossRef]

45. Lee, G.; Shim, H.-K.; Kwon, M.-H.; Son, S.-H.; Kim, K.-Y.; Park, E.-Y.; Yang, J.-K.; Lee, T.-K.; Auh, C.-K.; Kim, D.; et al. RNA virus accumulation is inhibited by ribonuclease activity of 3D8 scFv in transgenic Nicotiana tabacum. Plant. Cell Tissue Organ. Cult. (PCTOC) 2013, 115, 189-197. [CrossRef]

46. Lee, G.; Shim, H.-K.; Kwon, M.-H.; Son, S.-H.; Kim, K.-Y.; Park, E.-Y.; Lee, T.-K.; Lee, W.-R.; Auh, C.-K.; Kim, D.; et al. A nucleic acid hydrolyzing recombinant antibody confers resistance to curtovirus infection in tobacco. Plant. Cell Tissue Organ. Cult. (PCTOC) 2013, 115, 179-187. [CrossRef]

47. Hanke, L.; Vidakovics Perez, L.; Sheward, D.J.; Das, H.; Schulte, T.; Moliner-Morro, A.; Corcoran, M.; Achour, A.; Karlsson Hedestam, G.B.; Hallberg, B.M.; et al. An alpaca nanobody neutralizes SARS-CoV-2 by blocking receptor interaction. Nat. Commun. 2020, 11, 4420. [CrossRef] 